Gut, 1986, 27, 901-905

\title{
Faecal carcinoembryonic antigen in colorectal cancer patients
}

\author{
R S STUBBS, D M NADKARNI, AND H A MONSEY \\ From the Departments of Surgery and Biochemistry, Hillingdon Hospital, Middlesex
}

SUMmARY Carcinoembryonic antigen (CEA) has been measured in the faeces of large bowel cancer patients and control subjects to determine whether this measurement might be a useful aid in the diagnosis of large bowel cancer. The mean faecal CEA in 24 cancer patients fell significantly from $10.43 \pm 2.39 \mu \mathrm{g} / \mathrm{g}$ pre-operatively to $3.61 \pm 0.72 \mu \mathrm{g} / \mathrm{g}$ postoperatively $(\mathrm{p}<0.05)$. Pre-operative values were not related to either tumour stage or serum CEA. In 20 patients with no known colorectal disease the mean faecal CEA was $5.43 \pm 1.95 \mu \mathrm{g} / \mathrm{g}$ which was significantly lower than the mean pre-operative value in the cancer patients $(\mathrm{p}<0.05)$. In 14 patients with a variety of benign colonic diseases the mean faecal CEA was $7 \cdot 12 \pm 1.39 \mu \mathrm{g} / \mathrm{g}$ which was not significantly different from the mean pre-operative value in the cancer patients. Considerable overlap of values was observed between individual cancer and control patients making the test, as presently carried out, non-discriminatory. If the potential for making the test more cancer specific can be realised, however, faecal CEA determination may permit discrimination between cancer and non-cancer patients at a relatively early stage of disease.

Serum CEA measurement has regrettably not fulfilled its initial promise in the diagnosis of large bowel cancer. Although it is usually raised in patients with metastatic colorectal cancer, it is much less frequently raised in those with early, localised lesions $^{12}$ and it can be raised in a variety of non-malignant conditions. ${ }^{2}{ }^{3}$ Immunofluorescent techniques show that CEA is localised primarily to the cell membrane at the apical pole bordering on the glandular lumen. ${ }^{4}$ For this reason it might be expected that CEA is excreted/secreted into the bowel lumen and will be present in the faeces of patients with colorectal cancer. In 1972 Freed and Taylor showed this was indeed the case, ${ }^{5}$ although they also noted its presence in normal subjects. In 1975 similar findings were reported by Elias et at While both these groups found CEA in the stool of normal subjects, neither study had been truly quantitative. In 1979 Fujimoto et al reported raised CEA concentrations in the faeces of patients with colorectal cancer compared with controls and they commented that the CEA concentration was not related to the stage of disease. ${ }^{7}$ They concluded that

Address for correspondence: Mr R S Stubbs, Senior Registrar, Department of Surgery, Royal Postgraduate Medical School, Hammersmith Hospital, Ducane Road, London W12 0HS.

Received for publication 4 November 1985. faecal CEA measurement may be a useful adjunct in the diagnosis of colorectal cancer.

The purpose of the present study was to investigate this possibility. In particular we wished to measure faecal CEA in colorectal cancer patients before and after tumour resection and also in a variety of control subjects.

\section{Methods}

\section{PATIENTS}

Faecal CEA measurements were made in 24 patients with histologically proven large bowel cancer before surgery and again after resection of the primary tumour. Blood was drawn pre-operatively for measurement of serum CEA. Faecal CEA was also measured in 20 patients who had no known colorectal disease (control A) and in 14 patients who had a variety of non malignant colorectal diseases (control B).

Aqueous faecal extracts were prepared in the following manner. One entire stool specimen was collected and weighed $\left(\mathrm{W}_{1}\right)$. This was homogenised with $100 \mathrm{ml} 0.9 \% \mathrm{NaCl}$ and a small aliquot weighing $\left(\mathrm{W}_{2}\right)$ approximately $500 \mathrm{mg}$ was taken. To this was added $5 \mathrm{ml}$ phosphate buffered saline (PBS) $(\mathrm{pH} 7 \cdot 1)$ and the two were mixed thoroughly and 
incubated at $80^{\circ} \mathrm{C}$ for 10 minutes in a water bath. After centrifuging for 15 minutes at $600 \mathrm{~g}$ the supernatant was added to a further $5 \mathrm{ml}$ PBS (pH 7.1) and recentrifuged for a further 10 minutes at $600 \mathrm{~g}$. The volume of the supernatant was recorded (V) before filtration through a number 1 Whatman filter paper. The filtrate was stored at $-20^{\circ} \mathrm{C}$ for subsequent CEA assay. In all instances an extract was prepared within three days of stool collection, it having previously been ascertained by us (unpublished results) that no appreciable loss of CEA occurred over this interval. Sodium azide was added to the PBS to give a final concentration of $0.1 \%$ $(w / v)$ in order to prevent bacterial growth in the extracts.

Carcinoembryonic antigen assay was carried out using an enzyme linked immunoassay (ELISA) which has recently been developed by Hoffman LaRoche Ltd. Briefly, this involves the use of two monoclonal antibodies, one of which $(\mathrm{C}-19)$ is coated onto a polystyrene bead and the other (T84.66) is conjugated with horse radish peroxidase. Fifty microlitres of sample is mixed with $200 \mu$ l of conjugate and to this is added one bead. The mixture is incubated at $37^{\circ} \mathrm{C}$ for 60 minutes. After thorough washing of the bead with distilled water, $250 \mu \mathrm{l}$ of substrate (o-phenylenediamine) is added and the mixture is incubated at room temperature in the dark for 30 minutes. The enzymatic reaction is terminated by the addition of $1 \mathrm{ml} 1 \mathrm{~N} \mathrm{H}_{2} \mathrm{SO}_{4}$ and the optical density read at $492 \mathrm{~nm}$. The CEA concentration in the extract $\left(C E A_{E}\right)$, in $\mathrm{ng} / \mathrm{ml}$, is determined from a standard curve constructed during the assay. The sensitivity of this assay is approximately $0.5 \mathrm{ng} / \mathrm{ml}$.

The final concentration of CEA in the faecal sample $\left(C E A_{F}\right)$ is expressed in $\mu \mathrm{g} / \mathrm{g}$ wet weight of stool and was derived as follows:-

$$
\mathrm{CEA}_{\mathrm{F}}=\frac{\mathrm{CEA}_{\mathrm{E}} \times \mathrm{V} \times\left(\mathrm{W}_{1}+100\right)}{\mathrm{W}_{1} \times \mathrm{W}_{2} \times 1000} \mu \mathrm{g} / \mathrm{g}
$$

All patients with colorectal cancer were histologically staged according to the Dukes' classification ${ }^{8}$ with those with metastatic disease being referred to as stage $D$.

Results are expressed as mean $\pm \mathrm{SE}$ for each group of patients. The Student's paired $t$ test was used to determine the significance of the difference between pre-operative and postoperative samples from the colorectal cancer patients. Differences between the cancer and control patients were assessed with an unpaired $t$ test. A p value of less than 0.05 is taken to indicate a significant difference.
Results

COLORECTAL CANCER PATIENTS

Faecal CEA was measured before and after resection of the primary colorectal carcinoma in 24 patients. The mean age of these patients was 66.8 years with a range of 49 to 82 years. Mean \pm SE faecal CEA in this group was 10.43 $\pm 2.39 \mu \mathrm{g} / \mathrm{g}$ pre-operatively and this fell significantly $(\mathrm{p}<0.05)$ to $3.61 \pm 0.72 \mu \mathrm{g} / \mathrm{g}$ after resection of the primary tumour. (Fig. 1) It can be seen from Figure 2 that in the patients studied the range of faecal CEA values was similar for all stages of disease. In particular, the two patients with Dukes' A disease had appreciable levels of pre-operative faecal CEA which fell after resection of the tumour. By way of contrast, only four of the 24 patients had a raised serum CEA. One of these had Dukes' A disease, two had Dukes' $\mathrm{C}$ disease and one had stage $\mathrm{D}$ disease.

\section{CONTROL PATIENTS}

Faecal CEA was measured in 20 patients with no known colorectal disease (control A) whose ages ranged from 51 to 72 years with a mean of 64.8 years. The mean $\pm S E$ faecal CEA in these patients was $5.43 \pm 1.95 \mu \mathrm{g} / \mathrm{g}$ which was significantly less than that found pre-operatively in the cancer patients,

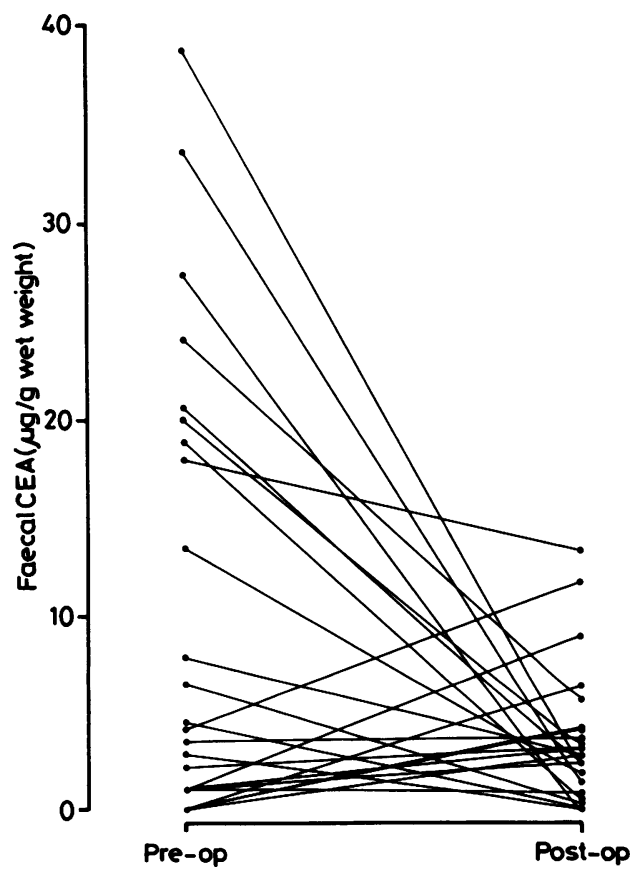

Fig. 1 Faecal CEA before and after resection of the large bowel primary cancer in 24 patients. 

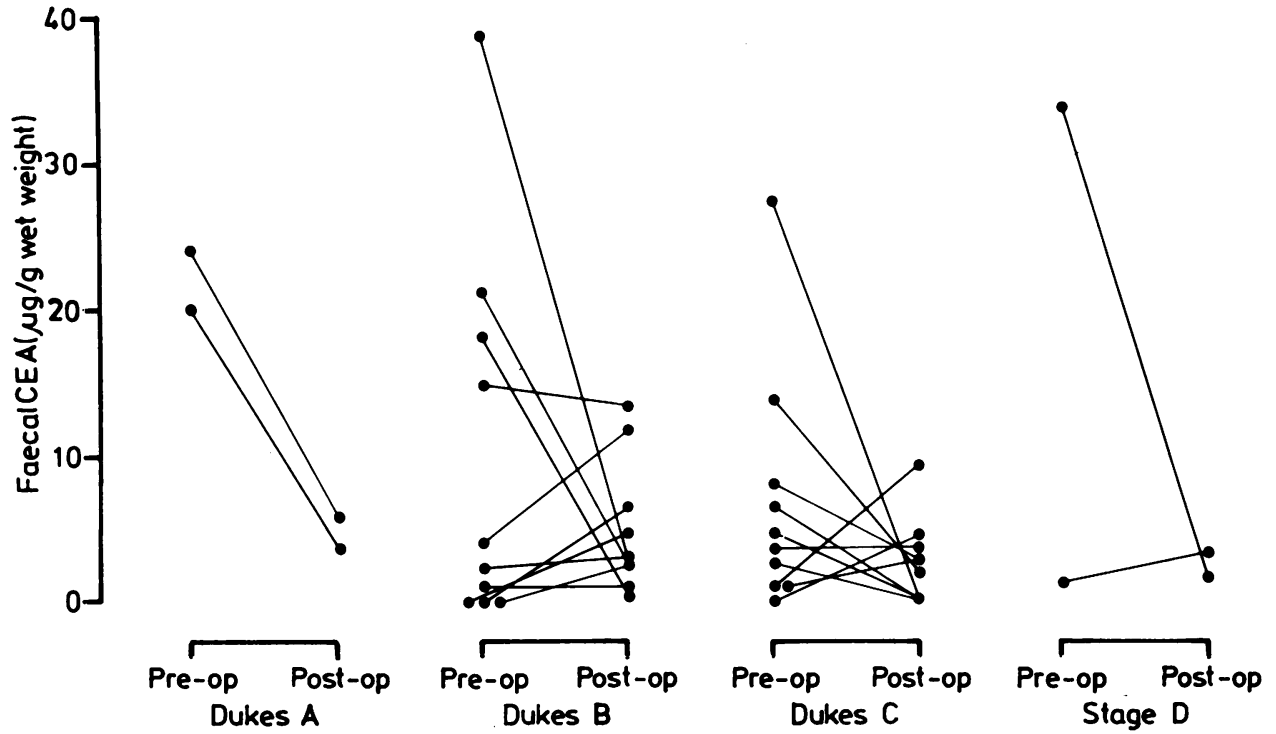

Fig. 2 Faecal CEA before and after resection of the large bowel primary cancer in 24 patients. Patients are grouped according to the pathologic stage of the disease.

and not significantly different from that found postoperatively in the cancer patients. Serum CEA was normal in all these 20 control subjects. In 14 patients with benign colorectal disease (control B) whose ages ranged from 54 to 80 years with a mean of 68.4 years the mean \pm SE faecal CEA was $7 \cdot 12 \pm 1 \cdot 39 \mu \mathrm{g} / \mathrm{g}$ which was not significantly different from that found pre-operatively in the cancer patients. The variety of non-malignant conditions affecting these 14 patients is shown in the Table. Faecal CEA results for each group of patients are shown in Figure 3.

\section{Discussion}

The results of the present study confirm previous reports that CEA or CEA-like material is to be found in the faeces of large bowel cancer patients and some normal subjects. ${ }^{5-7}$ Of particular interest is the observation that in the majority of colorectal

Table Diagnoses in 14 control patients with benign colorectal disease. (Control B)

\begin{tabular}{lr}
\hline Diagnosis & No \\
\hline Diverticular disease & 10 \\
Ulcerative colitis & 1 \\
Crohn's disease & 2 \\
Radiation proctitis & 1 \\
\hline
\end{tabular}

cancer patients with appreciable levels of faecal CEA pre-operatively, the level falls significantly after resection of the primary tumour. This is in

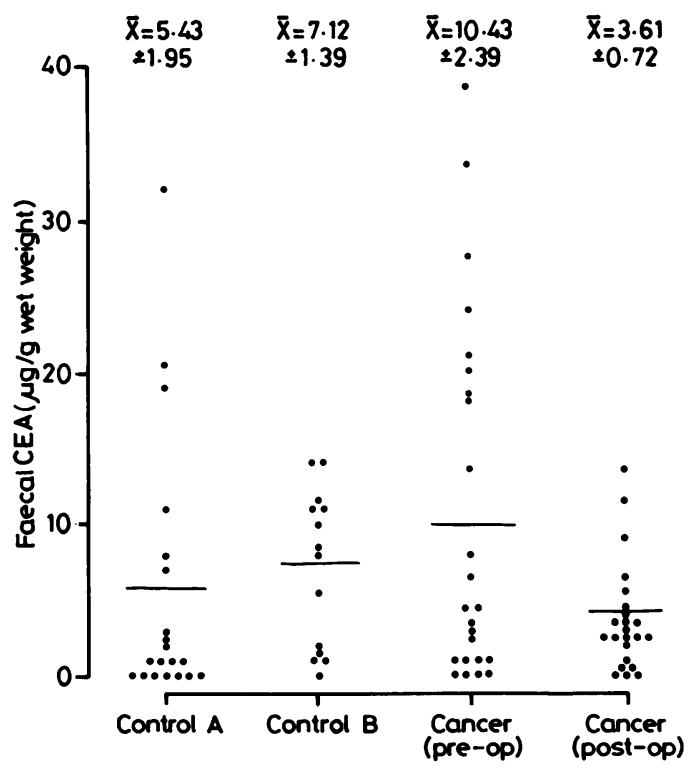

Fig. 3 Faecal $C E A$ values obtained in 20 patients with no known colorectal disease (control A), 14 patients with benign colorectal disease (control B) and 24 patients with large bowel cancer before and after resection of the primary tumour. 
accordance with the findings of Fujimoto $e t a l^{7}$ and makes it likely that much of the CEA detected in these patients does indeed originate in the tumour and not from elsewhere in the gut. It is of some consequence that the pre-operative faecal CEA in the cancer patients did not appear to relate particularly to the stage of the disease nor to the serum CEA. This again confirms the previous report on the subject by Fujimoto $e t a l^{7}$ and is perhaps not surprising as one might expect the faecal CEA to reflect the surface area which the tumour presents to the gut lumen, rather than the tumour mass per se. This finding, of course, lends hope to the possibility that faecal CEA may in the future permit early and perhaps even presymptomatic diagnosis of colorectal cancer. It is apparent, however, from the faecal CEA levels found in the control patients and particularly those with benign colonic diseases, that the measurement of CEA as carried out in this study is of low specificity. This result contrasts sharply with that of Fujimoto $e t$ al who reported a significantly higher faecal CEA in 22 colorectal cancer patients than in 20 control subjects. ${ }^{7}$ Although in our own studies there was a significantly higher mean faecal CEA in the cancer patients preoperatively than in controls with no known large bowel disease, there was considerable overlap of the values obtained in the two groups. When faecal CEA in the cancer patients was compared with that in patients with a variety of benign colonic disorders, however, no difference was observed. The discrepancy between the findings of Fujimoto's group and our own may well be accounted for by their selection of control patients. Although differences exist between the methods of CEA extraction and assay used by ourselves and Fujimoto, we do not think these would account for their better discrimination between cancer and control patients. Our own method of CEA extraction is almost identical to that used by them, except for our use of phosphate buffer ( $\mathrm{pH} 7 \cdot 1)$ as opposed to their acetate buffer $(\mathrm{pH} \mathrm{5 \cdot 0)}$. In our experience use of these two buffers does not produce substantially different results. (unpublished data) The radioimmunoassay used by Fujimoto's group used a polyclonal antibody and is similar to the RIA used by us in a previous study. ${ }^{9}$ In our experience this radioimmunoassay provided less discrimination between cancer and control patients than an ELISA utilising the T84.66 monoclonal antibody which we have used in the present study. Although our present method of faecal CEA extraction and assay shows little specificity for large bowel cancer, there is reason to believe this situation could perhaps be improved with the use of a more specific assay. From the studies of Burtin et $a l^{10}$ and Kuroki et al, ${ }^{11}$ it is apparent there are numerous non-CEA but CEA-like glycoproteins in normal colon and faeces which cross react in current CEA assay systems. Rogers et al have shown that some of these cross reactants are heat labile, while CEA itself is heat stable. ${ }^{12}$ We have certainly observed a considerable reduction in the measured CEA content of faecal extracts after heating which implies our assay is by no means specific for CEA, but is crossreacting with at least some of the heat labile non-CEA proteins in faeces. Cross reactivity with CEA-like faecal antigens coupled with variations in faecal excretion of these may explain those instances where faecal CEA remained relatively constant or even rose after resection of the tumour. We have previously reported a similar study to the present one in which the CEA extraction procedure was identical to that used here, but the assay procedure, as mentioned above, was by radioimmunoassay utilising a polyclonal antibody. ${ }^{9}$ Under those conditions large quantities of CEA were detected in the faeces of both cancer and non-cancer patients. While our present assay, which utilises two monoclonal antibodies, does appear to provide improved specificity for CEA, we still have not the means to discriminate cancer from non-cancer patients on the basis of faecal CEA. Nevertheless, it remains possible that more specific methods of CEA extraction and/or assay may provide us with the basis for a useful measurement for diagnosing colorectal cancer.

The investigators are indebted to Hoffman LaRoche Ltd, Nutley NJ, USA for financial support and the generous provision of CEA-EIA kits. The work was supported by a grant from the NW Thames Regional Health Authority.

\section{References}

1 Zamchek N, Moore TL, Dhar P, Kupchik H. Immunologic diagnosis and prognosis of human digestive tract cancer. N Engl J Med 1972; 286: 83-6.

2 A collaborative study of a test for carcinoembryonic antigen (CEA) in the sera of patients with carcinoma of the colon and rectum. A joint National Cancer Institute of Canada/American Cancer Society Investigation. Can Med Assoc J 1972; 107: 25-33.

3 Hansen HJ, Snyder JJ, Miller E et al. Carcinoembryonic antigen (CEA) assay. A laboratory adjunct in the diagnosis and management of cancer. Hum Pathol 1974; 5: 139-47.

4 Gold P, Krupey J, Ansari H. Position of the carcinoembryonic antigen of the human digestive system in ultrastructure of tumour cell surface. J Natl Cancer Inst 1970; 45: 219-225.

5 Freed DLJ, Taylor G. Carcinoembryonic antigen in faeces. $\mathrm{Br}$ Med J 1972; 1: 85-7.

6 Elias EG, Holyoke ED, Ming Chu T. Carcinoem- 
bryonic antigen (CEA) in feces and plasma of normal subjects and patients with colorectal cancer. Dis Col Rect 1974; 17: 38-41.

7 Fujimoto S, Kitsukawa Y, Itoh K. Carcinoembryonic antigen (CEA) in gastric juice or feces as an aid in the diagnosis of gastrointestinal cancer. Ann Surg 1979; 189: 34-8.

8 Dukes CE, Bussey HJR. The spread of rectal cancer and its effect on prognosis. $B r J$ Cancer 1958; 12: 309-20.

9 Stubbs RS, McLean Baird I, Shively JE. Faecal carcinoembryonic antigen (CEA) in patients with colorectal cancer. [Abstract] Gut 1984; 25: A1170.

10 Burtin $P$. The carcinoembryonic antigen of the digestive system (CEA) and the antigens cross reacting with it. Ann Immunol 1978; 129C: 185-198.

11 Kuroki M, Koga Y, Matsuoka Y. Purification and characterisation of carcinoembryonic antigen-related antigens in normal adult feces. Cancer Res 1981; 41: 713-20.

12 Rogers GT, Keep PA. CEA-like activity in normal colon tissue. Eur J Cancer 1980; 16: 127-31. 